\title{
Periádica Eletrânica

\section{MONITORAMENTO DO APORTE DE SÓLIDOS SUSPENSOS NAS ÁGUAS DA BACIA HIDROGRÁFICA DO RIO PIRAPÓ - PR}

\author{
Cássia Maria Bonifácio ${ }^{1}$ \\ Diogo Yukio Uema ${ }^{2}$ \\ Célia Regina Granhen Tavares ${ }^{3}$
}

\begin{abstract}
RESUMO
Esta pesquisa teve por objetivo a aplicação de metodologias já existentes com intuito de quantificar e monitorar os sólidos totais, dissolvidos e não filtráveis nas águas superficiais da bacia hidrográfica do rio Pirapó - PR, para resultar em uma análise de qualidade de água. O monitoramento da bacia se deu entre os meses de janeiro a dezembro de 2014, com campanhas mensais. Procurou-se maneiras de seguir uma proposta que levasse em consideração os fatores naturais e antrópicos, com influencia da geologia/pedologia e uso do solo, para caracterizar a predominância das partículas encontradas. O método utilizado foi o gravimétrico e a unidade de medida é expressa em $\mathrm{mg} \mathrm{L}^{-}{ }^{1}$. Os resultados mostraram que os pontos locados a jusante da bacia apresentam um aporte maior de sólidos, devido ao processo de transporte e deposição fluvial, e, que a maior parte dos sólidos nas águas correspondem a partículas de frações médias, resultantes de solos provenientes do Arenito e lançamentos de efluentes.
\end{abstract}

PALAVRAS-CHAVE: Qualidade da água. Solos. Sedimentos Fluviais.

\section{SOLID APORTE MONITORING SUSPENDED IN BASIN WATERS OF RIVER PIRAPÓ - PR}

ABSTRACT - This research aims to apply existing methodologies aiming to quantify and monitor the total solids, dissolved and not filterable in surface waters of river basin Pirapó - PR, to result in an analysis of water quality. The monitoring of the basin occurred between the months of January to December 2014, with monthly campaigns. Sought ways to follow up a a proposal that would take into account the natural and anthropogenic factors, with influences of geology/pedology and land use to characterize the predominance of particles found. The method used was the gravimetric and the unit of measurement is expressed in $\mathrm{mg} \mathrm{L}-1$. The results showed that the points leased downstream of the basin have a higher amount of solids due to transport and river deposition process, and that most of the solids in the water corresponds to an average particle fractions, resulting from soils from Sandstone and effluent discharges.

KEYWORDS: Water quality, Soils, Fluvial sediments.

\footnotetext{
${ }^{1}$ Doutoranda em Geografia, Universidade Estadual de Maringá, Bolsista CNPq. cassiabonifacio@hotmail.com

${ }_{2}^{2}$ Graduando em Geografia, Universidade Estadual de Maringá, Bolsista CNPq.

${ }^{3}$ Prof. Dra. do Departamento de Engenharia Química, Universidade Estadual de Maringá.
} 


\section{MONITOREO DE APORTE SÓLIDAS SUSPENDIDAS EN AGUAS DE LAS CUENCAS DE RÍO PIRAPÓ - PR}

RESUMEN - Esta investigación tiene como objetivo aplicar metodologías existentes con el objetivo de cuantificar y monitorear los sólidos totales disueltos y no filtrable en las aguas superficiales de la cuenca del río Pirapó - PR, para dar lugar a un análisis de la calidad del agua. El monitoreo de la cuenca se produjo entre los meses de enero a diciembre de 2014, con las campañas mensuales. Se buscó maneras de seguir una propuesta que tenga en cuenta los factores naturales y antropogénicos, con influencias de la geología/edafología y uso de la tierra para caracterizar el predominio de partículas que se encuentran. El método utilizado fue el gravimétrico y la unidad de medida se expresa en mg L-1. Los resultados mostraron que los puntos arrendados aguas abajo de la cuenca tienen una mayor cantidad de sólidos debido al transportar y proceso de deposición de río, y que la mayoría de los sólidos en el agua corresponde a un promedio de fracciones de partículas, resultante de suelos de piedra arenisca y descargas de efluentes.

PALABRAS CLAVE: La calidad del agua, Suelos, Sedimentos fluviales.

\section{INTRODUÇÃO}

Nas últimas décadas, com o desenvolvimento da urbanização, das tecnologias e principalmente da agricultura, os problemas ambientais como erosão e poluição, proporcionados por essa ação antrópica vem se agravando. As mudanças ambientais, ocasionadas pela ação antrópica, como a erosão e a poluição têm se intensificado a nível mundial (FREIRE, 2010).

A erosão do solo pode ser entendida como sendo o transporte de partículas de solo, que são carreadas para os corpos d'água, em eventos de precipitação. Está relacionada ao tipo de solo, quantidade de água precipitada, declividade do terreno e principalmente ao uso da terra (BONIFÁCIO, 2013). E, não somente um fenômeno físico, mas também um problema social e econômico. Resulta, fundamentalmente, de uma inadequada relação entre o solo e o homem (PIMENTEL,1997).

Considerando os processos de erosão, transporte e deposição, é possível ter ideia do quanto de matéria detrítica está sendo transportada pelos rios em forma de sólidos em suspensão. Isso porque, o processo acelerado de erosão ocorre quando há alteração do equilíbrio natural entre a perda e a recuperação do solo, potencializando prejuízos, inclusive monetários (BRITO, 2012).

Conforme os estudos de Bertoni e Neto (1999) a água superficial, que não pode ser infiltrada, é o maior agente transportador de partículas do solo. O que pode 
ocasionar também no transporte de poluentes, ligados a essas partículas. Ou seja, a poluição pode ser provocada por ação antrópica ou por ação natural (BRAGA, 2005).

A carga detrítica nos cursos de água é uma mistura de partículas de várias espécies, tamanhos e formas. Uma parcela delas nos cursos de água é obtida pela ação erosiva que as águas exercem sobre as margens e fundo do leito. A maior parte, entretanto, é fornecida pela remoção detrítica das vertentes. Por essa razão desde há muito tempo reconhece-se que o transporte dos sedimentos é governado pelos fatores hidrológicos, que controlam as características e o regime dos cursos de água (CHRISTOFOLETTI, 1988).

Todavia, é importante destacar que os agentes naturais, também influenciam na qualidade dos recursos hídricos. Dentre estes, é possível citar os óxidos de ferro e manganês, que são abundantes em diversos tipos de solos, inclusive na área de estudo, a bacia hidrográfica do rio Pirapó - PR. São solos originados por rochas sedimentares, apesar de não apresentarem coloração evidente, pela falta de óxidos, estão presentes em maior quantidade, pela questão de sua textura, que é mais propícia à lavagem, promovida pela precipitação.

Sendo assim, em relação à área de estudo, a bacia hidrográfica do rio Pirapó tem sua nascente em área urbana, todavia, ao longo de seu trajeto, apresenta usos da terra misto, urbano e rural. Nas áreas urbanas é possível destacar o carreamento de partículas devido à intensa impermeabilização do solo, já em meio rural, destinado à produção agrícola intensiva, ocorre à degradação dos atributos físicos do solo, resultando também no aporte de materiais sólidos e outras substâncias para o curso d'água (SALA, 2005; SCHNEIDER, 2009; FREIRE, 2010).

Nesse contexto, Alves et al., (2008), Schneider (2009) e Freire (2010) reportam que a bacia hidrográfica do rio Pirapó apresenta problemas recorrentes de poluição dos cursos d'agua, erosão das áreas de entorno, e deposição de sedimentos no leito dos rios. Sendo assim, a motivação deste estudo tem base nos problemas ambientais causados pelo transporte de sedimentos para os cursos d'água da bacia hidrográfica. Este fato justifica o estudo, fornecendo dados sobre a qualidade da água, com base no transporte de sedimentos, que colaboram para a elaboração de projetos de contenção e prevenção dos processos erosivos, propondo medidas de recuperação para a bacia. 


\section{OBJETIVOS}

O trabalho teve como objetivo principal monitorar o parâmetro de sólidos: totais, dissolvidos e não filtráveis, presentes nas águas superficiais de determinados pontos, na bacia do rio Pirapó - PR. A fim de avaliar o potencial de poluição difusa dos cursos d'água, em relação à Formação geológica e pedológica e os usos do solo.

\section{METODOLOGIA}

A bacia hidrográfica do rio Pirapó (Figura 1) situa-se a Norte do Estado do Paraná, entre as latitudes $22^{\circ} 32^{\prime} 30^{\prime \prime} \mathrm{S}$ e $23^{\circ} 36^{\prime} 18^{\prime \prime} \mathrm{S}$, e longitudes $51^{\circ} 22^{\prime} 42^{\prime \prime} \mathrm{W}$ e $52^{\circ} 12^{\prime} 30^{\prime \prime} \mathrm{W}$, sendo afluente da margem sul (esquerda) do rio Paranapanema.

Figura 1: Localização da bacia hidrográfica do rio Pirapó - PR.

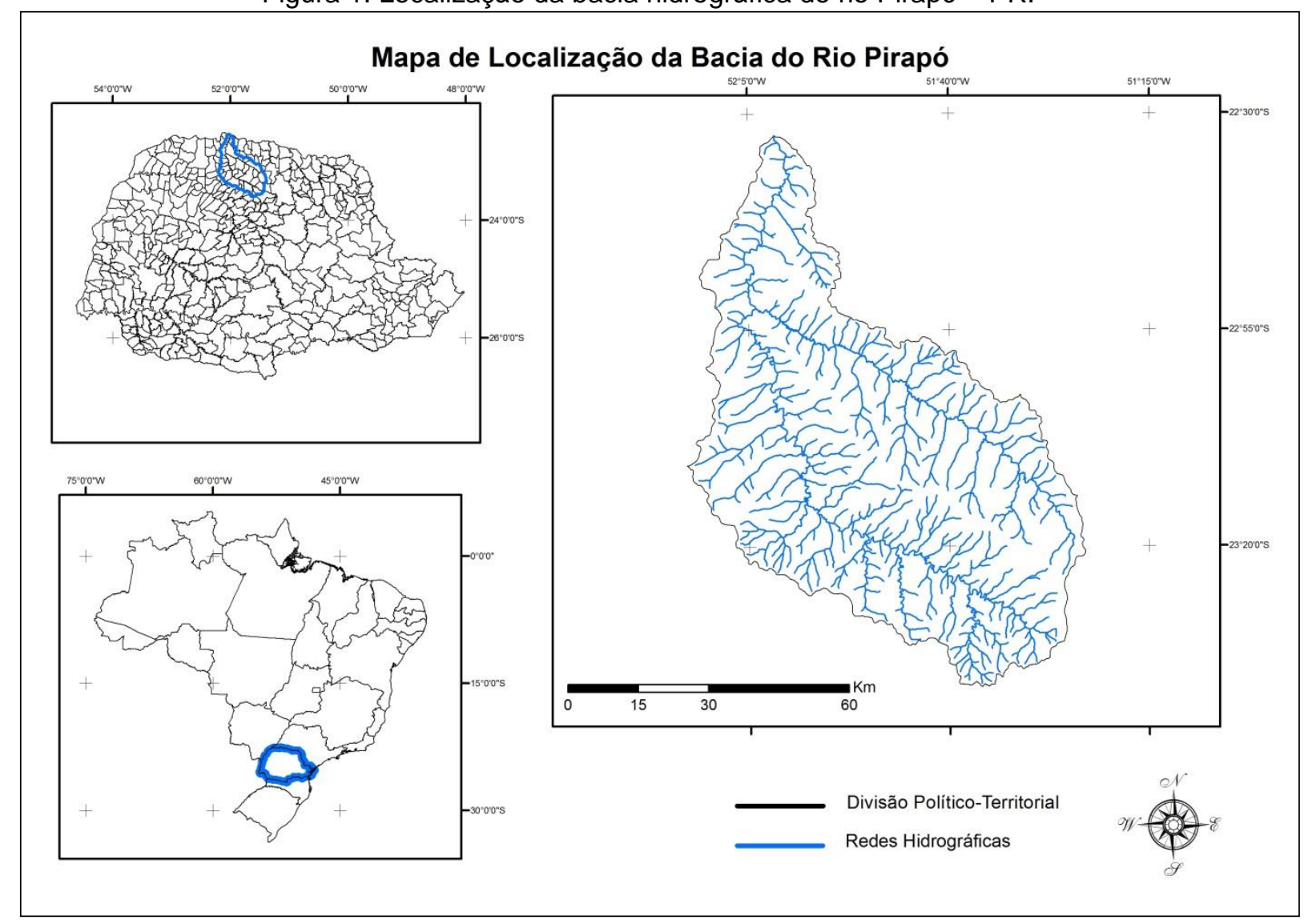




\section{Fórum Ambiental}

da Alta Paulista

Volume 11, Número 06, 2015

Planejamento e Gestão dos Recursos Hídricos

A área da bacia é ocupada principalmente por culturas temporárias (63,7\%) e pelas estruturas urbanas $(29,1 \%)$, enquanto a cobertura vegetal está restrita a apenas $7,2 \%$ do original (MELLO, 2009). Ou seja, devido ao uso misto, o carreamento de partículas é influenciado tanto pela compactação e como pela redução da infiltração, que ocasiona o aporte de materiais sólidos e outras substâncias para o curso d'água.

Para representar satisfatoriamente a bacia hidrográfica do rio Pirapó (Figura 2), foram coletadas amostras de água em cinco pontos, já estipulados (Tabela 1). A bacia foi dividida em duas sub-bacias, conforme a classificação em unidades de paisagem e Formação geológica, o que se justifica pela diferença entre os compartimentos locais e tipos de solo relacionados à geologia, lembrando que, alguns pontos estão em área de contato arenito/basalto.

Figura 2: Localização dos pontos de coleta na bacia hidrográfica do rio Pirapó - PR.

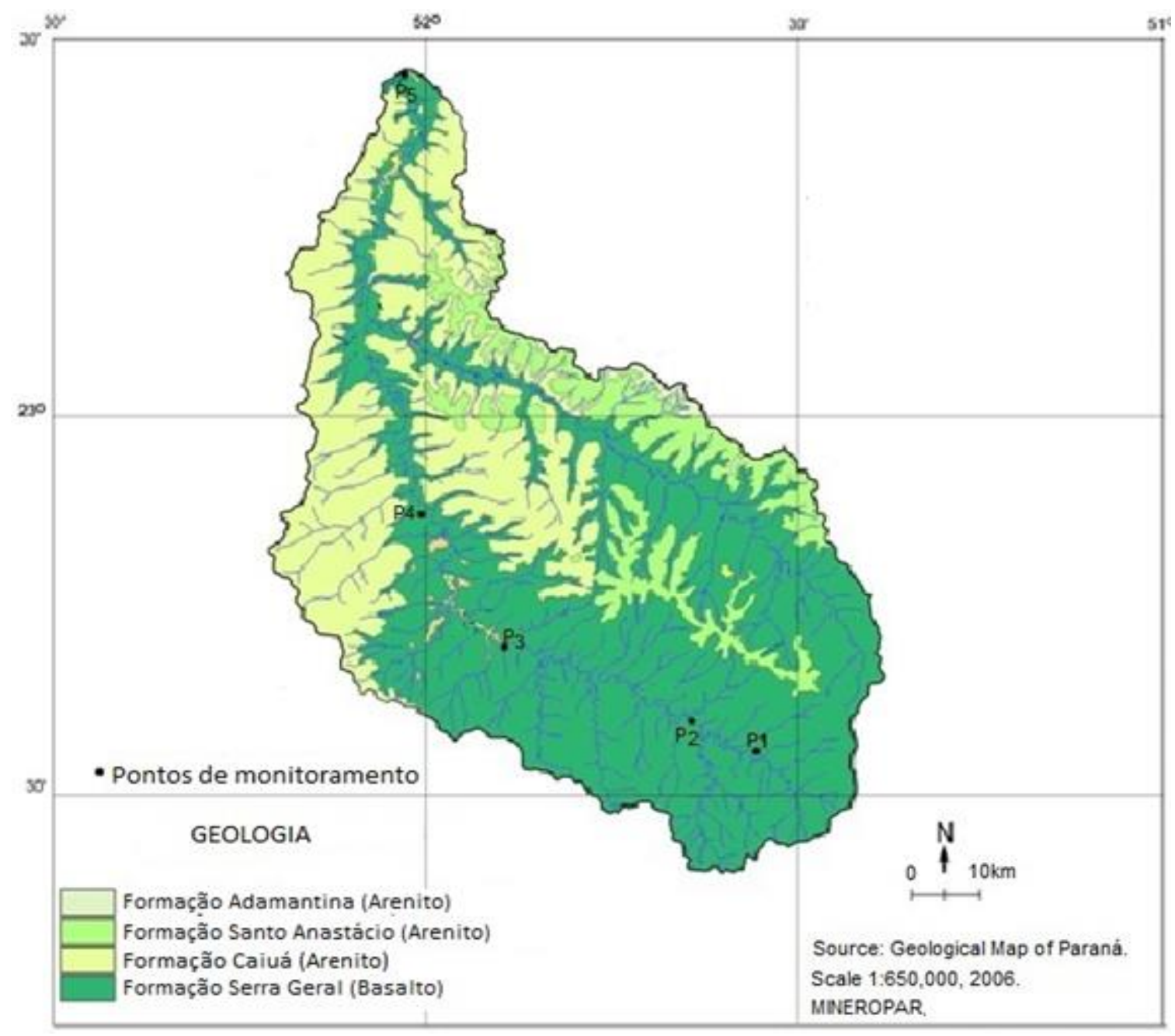


Tabela 1: Cursos d'água de coleta na bacia hidrográfica do rio Pirapó - PR.

\begin{tabular}{|c|c|c|c|c|c|}
\hline & Pontos & Local & Latitude & Longitude & $\begin{array}{l}\text { Altitude } \\
\text { (m) }\end{array}$ \\
\hline \multirow{3}{*}{ 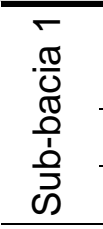 } & 1 & $\begin{array}{l}\text { A jusante do córrego Água do } \\
\text { Abutre }\end{array}$ & $23^{\circ} 26^{\prime} 59^{\prime \prime} \mathrm{S}$ & $51^{\circ} 33^{\prime} 19^{\prime \prime W}$ & 553 \\
\hline & 2 & A montante do ribeirão Vitória & $23^{\circ} 24^{\prime} 02^{\prime \prime S}$ & $51^{\circ} 38^{\prime} 45^{\prime \prime W}$ & 454 \\
\hline & 3 & A jusante do ribeirão Guarujá & $23^{\circ} 18^{\prime} 25^{\prime \prime} \mathrm{S}$ & $51^{\circ} 53^{\prime} 59^{\prime \prime} \mathrm{W}$ & 393 \\
\hline \multirow{2}{*}{ 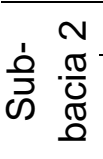 } & 4 & A montante do ribeirão Flórida & $23^{\circ} 07^{\prime} 84^{\prime S} \mathrm{~S}$ & $52^{\circ} 00^{\prime} 33^{\prime \prime} \mathrm{W}$ & 377 \\
\hline & 5 & $\begin{array}{l}\text { A jusante do ribeirão Água do } \\
\text { Pau d'Alho }\end{array}$ & $22^{\circ} 32^{\prime} 90^{\prime \prime S}$ & $52^{\circ} 01^{\prime} 72^{\prime \prime W}$ & 269 \\
\hline
\end{tabular}

As coletas realizaram-se em uma frequência mensal, no período de janeiro a dezembro de 2014. As amostras foram coletadas de forma pontual, no ponto central da seção do curso d'água, armazenadas em frascos de polietileno (2L), e mantidas em resfriamento. A sistemática de preservação das amostras até o momento da análise seguiu a metodologia proposta no Standard Methods for Examination of Water and Wastewater (APHA, 1998).

As análises foram realizadas no Laboratório de Gestão, Preservação e Controle Ambiental (LGPCA) do Departamento de Engenharia Química da Universidade Estadual de Maringá (UEM). Os parâmetros realizados foram sólidos suspensos totais, sólidos suspensos dissolvidos e sólidos suspensos não filtráveis. Para garantir confiabilidade dos resultados obtidos, os testes foram executados em duplicata, possibilitando o cálculo do resultado médio.

A divisão dos sólidos é feita por tamanho, por ser uma divisão prática. Todavia é possível afirmar que, partículas de menores dimensões, capazes de passar por um papel de filtro de tamanho especificado, correspondem aos sólidos dissolvidos, enquanto que as de maiores dimensões, retidas pelo filtro, são consideradas sólidos em suspensão (VON SPERLING, 1996).

\section{Resultados}

As coletas de campos foram realizadas mensalmente, como planejado, bem como as análises laboratoriais. Os cinco pontos de monitoramento mostraram resultados satisfatórios, conforme o esperado, para a Formação geológica e 


\section{Periádica Eletranica

pedológica, o que se justifica pela diferença entre os compartimentos locais e tipos de solo relacionados à geologia.

Na tabela 2 é possível observar os diferentes tipos de solo, em cada ponto, e seus diferentes usos, que, são fatores importantes para a qualidade de água e planejamento e gestão da bacia.

Tabela 2: Solos, usos do solo e cidades próximas aos pontos de monitoramento.

\begin{tabular}{c|cc|c}
\hline \multirow{2}{*}{ Pontos } & Tipo de solo & Uso do solo & Cidade próxima \\
\hline 1 & Nitossolo Vermelho & Pastagem & Mandaguari \\
\hline 2 & Argissolo Vermelho & Cana-de-açúcar & Astorga \\
\hline 3 & Nitossolo Vermelho & Pastagem/Indústria & Maringá \\
\hline 4 & Argissolo Vermelho & Mandioca, Cana e Milho & Atalaia/Flórida \\
\hline 5 & Nitossolo Vermelho & $\begin{array}{c}\text { Cana-de-açúcar e } \\
\text { Eucalipto }\end{array}$ & Jardim Olinda \\
\hline
\end{tabular}

Os sólidos podem ser considerados como constituintes intemperizados da rocha, em estado de solução química, determinado como sólido total, as partículas que restam na cápsula após a evaporação de uma porção de amostra e sua posterior secagem em estufa a $103-105^{\circ} \mathrm{C}$ até peso constante, ou sólido suspenso, que é a porção dos sólidos totais que fica retida em um filtro membrana, que propicia a retenção de partículas de diâmetro maior ou igual a 1,2 $\mu \mathrm{m}$.

As figuras 3,4 e 5 mostram os valores obtidos por monitoramento do parâmetro sólidos totais (SST), dissolvidos (SSD) e não filtráveis (SSNF), respectivamente, entre os meses de janeiro a dezembro de 2014. 
Figura 3: Monitoramento do parâmetro de SST na bacia hidrográfica do rio Pirapó - PR.

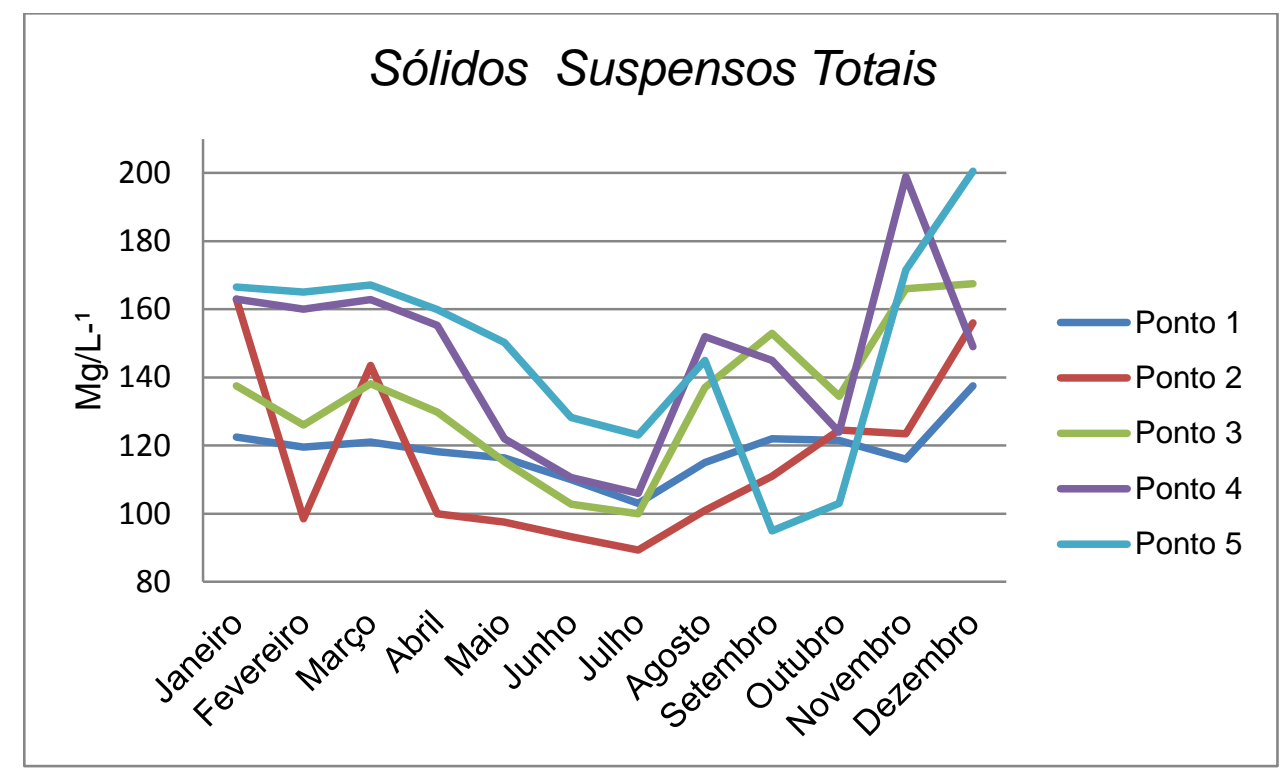

Conforme apresentado, para o parâmetro de sólidos totais (Figura 3) é possível observar acréscimos nos valores dos pontos 5, 4 e 3, do médio curso para a jusante. O ponto 3, apesar de estar sobre o basalto, sofre a dinâmica dos processos urbanos do município de Maringá - o maior centro urbano da bacia hidrográfica do rio Pirapó, podendo estar sobre influência de efluentes e demais contaminantes.

E, o ponto 4, apresenta tais valores devido a sua localização em solos de textura média e, por sua vez também, a diversidade do uso agrícola, com culturas de cana-de-açúcar, mandioca e milho e, é interessante destacar que são culturas temporárias, que por si só colaboram para o aporte de sólidos em épocas de colheita e replantio. Já o ponto 5 , está à jusante da bacia hidrográfica e, recebe toda a carga de sólidos dos demais afluentes. 
Figura 4: Monitoramento do parâmetro de SSD na bacia hidrográfica do rio Pirapó - PR.

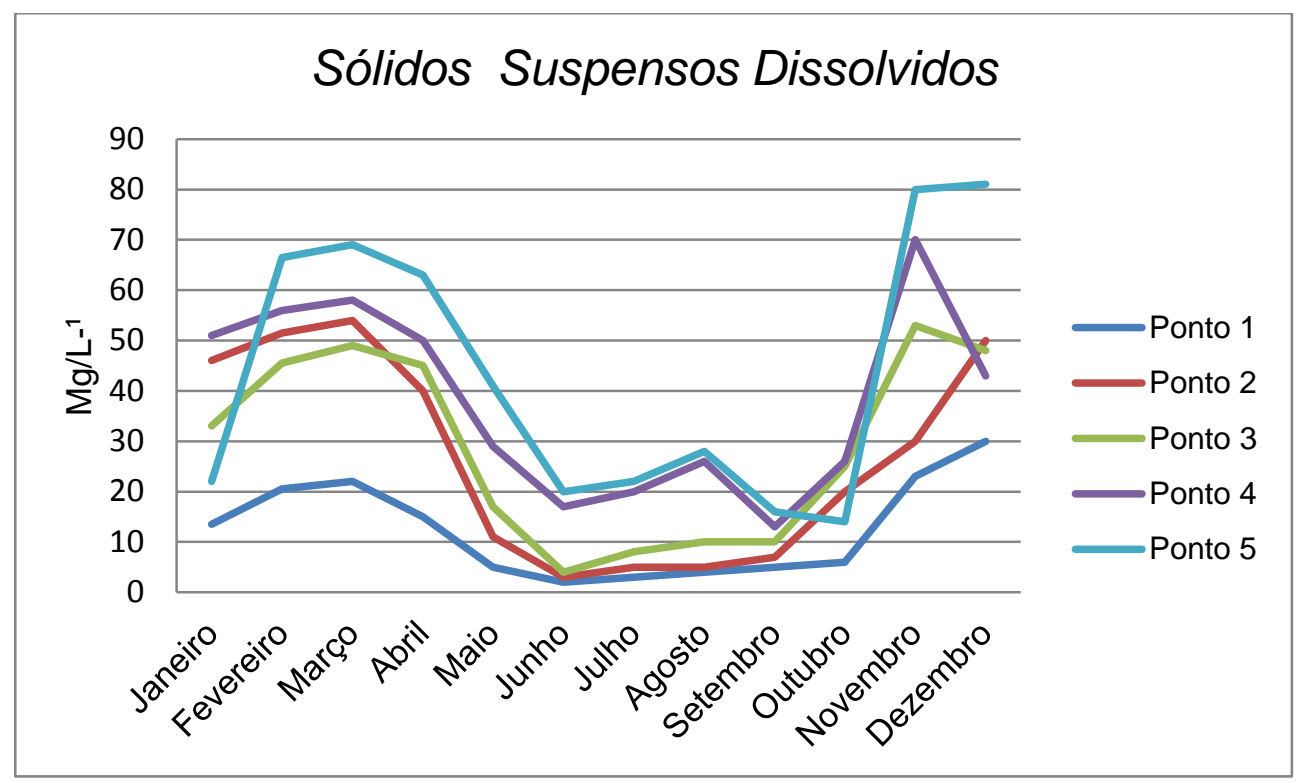

Os resultados dos sólidos dissolvidos (Figura 4) demonstram que nem todas as frações passam pela membrana, indicando que, muitas vezes, o aporte de sólidos não se caracteriza por texturas finas, como a argila, mas, preferencialmente por textura média, proveniente do Arenito. É perceptível a variação do aporte de sólidos, com acréscimo nos meses de primavera e verão e menores valores nos meses de outono e inverno. Isso por sua vez pode ser explicado pela dinâmica climática local, onde períodos de outono e inverno são caracterizados por estiagem, pouca precipitação. 
Figura 5: Monitoramento do parâmetro de SSNF na bacia hidrográfica do rio Pirapó - PR.

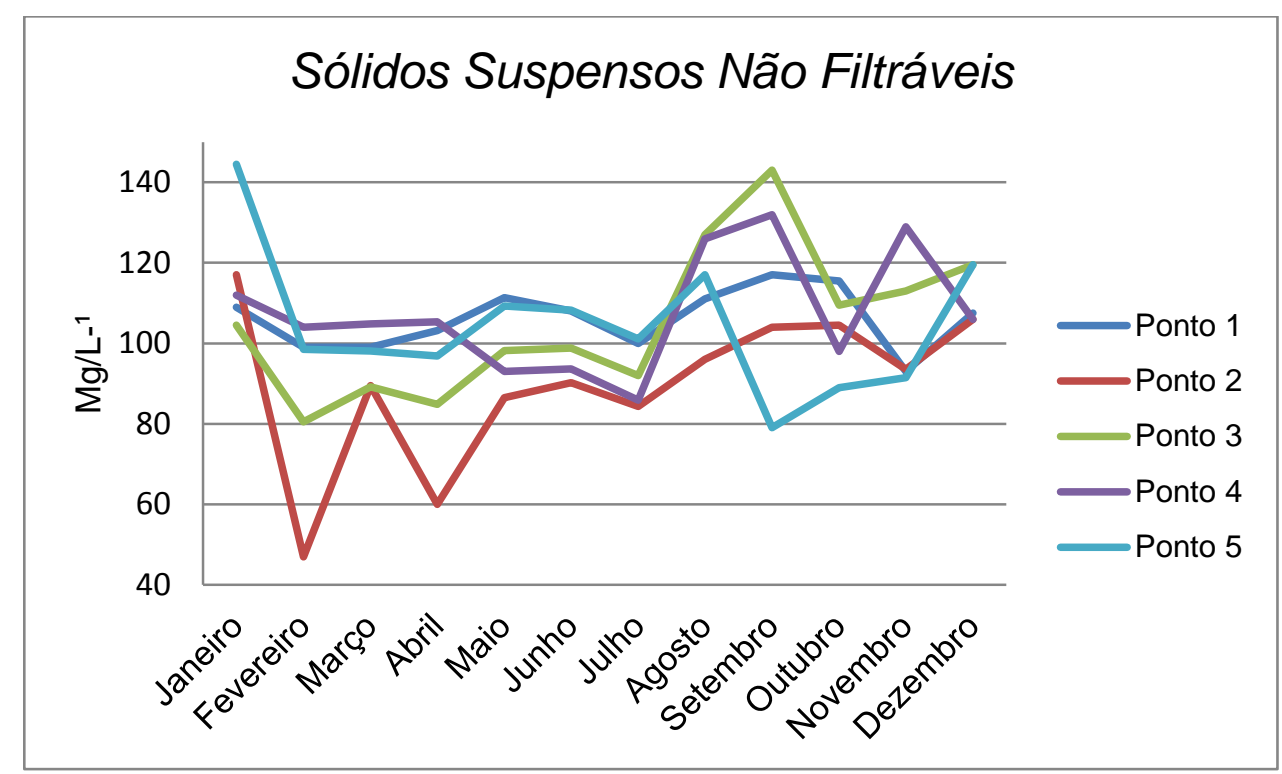

E, conforme é possível observar nos sólidos não filtráveis (Figura 5), as maiores frações de partículas caracterizam o aporte de sedimentos na bacia, podendo apresentar textura média - pela geologia/solos ou, contudo a aglutinação das partículas do regolito com poluentes urbanos e rurais.

É interessante descatar a diferença na cor da água (Figura 6) entre pontos de distintas Formações geológicas. Os componentes do solo se tornam os agentes influênciadores, nos pontos onde se encontram os solos formados por Arenitos, a água é mais clara, já nas partes sobre o Basalto, a cor da água é mais escura/avermelhada, essa cor se deve pelo óxido de ferro encontrado nos solos basálticos.

Figura 6 : Diferença da cor entre os filtros: a. Amostra sobre o Basalto, b. Amostra sobre o Arenito.

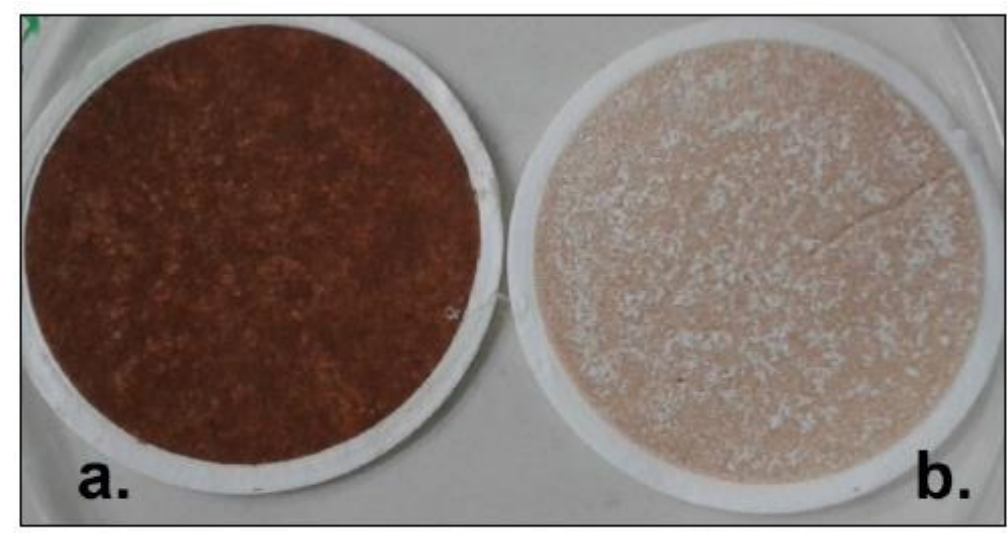




\section{Conclusões}

As informações obtidas a partir do método de filtração e pesagem das amostras evidenciaram maior concentração de sólidos nos pontos a jusante da bacia hidrográfica, essa progressão acontece a partir de fatores geofísicos e antrópicos.

Pode-se citar que, a partir da geologia local se formaram solos mais friáveis, ou seja, fácil de erodirem, que somados à ação antrópica, com lançamentos de efluentes, caracteriza a o maior aporte de texturas maiores para a jusante.

Fatores climáticos, juntamente com as reações químicas existentes entre os argilominerais, facilitam também o processo de detritos nas águas da bacia, sendo notável o aumento dos sólidos nos meses caracterizados por maior precipitação primavera e verão. Todavia é necessário destacar que, em nenhum momento do período de monitoramento os resultados ultrapassaram o valor estipulado pela Resolução CONAMA 357/2005 para corpos d'água Classe II.

\section{Agradecimentos}

Os autores agradecem ao CNPq e a FINEP.

\section{Referências}

ALVES, E. C.; SILVA, C. F.; COSSICH, E. S.; TAVARES, C. R. G.; FILHO, E. E. S.; CARNIEL, A. Avaliação da qualidade da água da bacia do rio Pirapó - Maringá, Estado do Paraná, por meio de parâmetros físicos, químicos e microbiológicos. Acta Scientiarum Technology, v. $30, n$. 1, p. 39-48. 2008.

APHA. American Public Health Association. Standard Methods for the Examination of Water and Wastewater. American Public Health Association. Washington, D.C., 1998, 1600 p. BERTONI, J.; LOMBARDI NETO, F. Conservação do solo. 4. Ed. São Paulo: Ícone, 1999, p. 68-72.

BERTONI, J.; LOMBARDI NETO, F. Conservação do solo. 4. Ed. São Paulo: Ícone, 1999, p. 68-72.

BONIFÁCIO, C. M. Avaliação da fragilidade ambiental em bacias hidrográficas do alto vale do rio Pirapó, Norte do Paraná: Proposta metodológica. Universidade Estadual de Maringá. Dissertação. Programa de Pós Graduação em Geografia. 110p. 2013.

BRAGA, B.; HESPANHOL, I.; CONEJO, J. G. L.; BARROS, M. T. L.; SPENCER, M.; PORTO, M.; NUCCI, N.; JULIANO, N.; EIGER, S. Introdução à Engenharia Ambiental: o desafio do desenvolvimento sustentável. 2ª Ed. São Paulo: Person Prentice Hall, 2005. 


\section{Periádica Eletranica

BRITO, A. O. Estudos da erosão no ambiente urbano, visando planejamento e controle ambiental no distrito federal. Dissertação de mestrado em ciências florestais. Universidade de Brasília, faculdade de tecnologia. Brasília/DF: fevereiro, 2012.

CHRISTOFOLETTI, A. Geomorfologia Fluvial. Volume I - O canal fluvial. Editora Edgarr Blücher LTDA. São Paulo-SP, 1988.

FREIRE, R. Monitoramento da qualidade da água da bacia hidrográfica do ribeirão Maringá. 2010. 199 p. Dissertação (Mestrado em Engenharia Química), Universidade Estadual de Maringá, Maringá.

MELLO, W. S. Análise ambiental da bacia Hidrográfica do Ribeirão Maringá com apoio de imagens de satélite. 2009. 37p. Monografia (Especialização em Gestão de Recursos Hídricos) Departamento de Engenharia Química. Universidade Estadual de Maringá, Maringá.

SALA, M. G. Análise da fragilidade ambiental na bacia do Ribeirão Maringá - PR. 2005. 164p. Dissertação (Mestrado em Geografia) - Departamento de Geografia. Universidade Estadual de Maringá, Maringá.

SCHNEIDER, R. M. Qualidade da Água e deposição de sedimentos em trechos da Bacia Hidrográfica do Rio Pirapó representados pelo Ribeirão Maringá. 2009.

150p. Tese (Doutorado em Engenharia Química) - Departamento de Engenharia Química. Universidade Estadual de Maringá, Maringá.

VON SPERLING, M. V. Princípio do tratamento biológico de águas residuárias. IN: Introdução à qualidade das águas e ao tratamento de esgotos. 1995.p. 